\title{
In Situ Ion Irradiation of Zirconium Carbide
}

\author{
Christopher J. Ulmer ${ }^{\mathrm{a}, *}$, Arthur T. Motta ${ }^{\mathrm{a}}$, Mark A. Kirk ${ }^{\mathrm{b}}$ \\ ${ }^{a}$ Department of Mechanical and Nuclear Engineering, The Pennsylvania State University, \\ University Park, PA 16802, USA \\ ${ }^{b}$ Nuclear Engineering Division, Argonne National Laboratory, Argonne, IL 60439, USA
}

\begin{abstract}
Zirconium carbide $(\mathrm{ZrC})$ is a candidate material for use in one of the layers of TRISO coated fuel particles to be used in the Generation IV high-temperature, gas-cooled reactor, and thus it is necessary to study the effects of radiation damage. The microstructural evolution of $\mathrm{ZrC}_{\mathrm{x}}$ under irradiation was studied in situ using the Intermediate Voltage Electron Microscope (IVEM) at Argonne National Laboratory. Samples of nominal stoichiometries $\mathrm{ZrC}_{0.8}$ and $\mathrm{ZrC}_{0.9}$ were irradiated in situ using $1 \mathrm{MeV} \mathrm{Kr}^{2+}$ ions at various irradiation temperatures $(\mathrm{T}=20 \mathrm{~K}-1073 \mathrm{~K})$. In situ experiments made it possible to continuously follow the evolution of the microstructure during irradiation using diffraction contrast imaging. Images and diffraction patterns were systematically recorded at selected dose points. After a threshold dose during irradiations conducted at room temperature and below, black-dot defects were observed which accumulated until saturation. Once created, the defect clusters did not move or get destroyed during irradiation so that at the final dose the low temperature microstructure consisted only of small defect clusters. No long-range migration of the visible defects or dynamic defect creation and elimination were observed during irradiation, but some coarsening of the microstructure with the formation of dislocation loops was observed at higher temperatures. The irradiated microstructure was found to be only weakly dependent on the stoichiometry. Keywords: nuclear materials, zirconium carbide, ion irradiation, defects
\end{abstract}

\footnotetext{
* Corresponding author

Email address: cju5002@psu.edu (Christopher J. Ulmer)
}

Preprint submitted to Elsevier

August 4, 2015 


\section{Introduction}

Generation IV nuclear reactors are conceived to provide improvements in sustainability, safety, reliability, economics and proliferation resistance over current reactors [1]. One such reactor concept is the high-temperature gas-cooled 5 reactor or, more specifically, the very-high-temperature reactor (VHTR). The VHTR concept utilizes helium coolant with high outlet temperature to improve thermal energy conversion efficiency. The tristructural isotropic (TRISO) fuel, a type of coated fuel particle, is the basic fuel form of the VHTR [2].

The TRISO fuel particle design includes a load-bearing $\mathrm{SiC}$ layer which serves as a barrier to fission gas release. However, there are some limitations for the use of $\mathrm{SiC}$ in the TRISO fuel design. SiC may be thermally unstable in the temperature range that could be reached during accident conditions so that it could undergo a $\beta$-SiC to $\alpha-\mathrm{SiC}$ transformation, resulting in failure of the layer and the consequent release of fission products [3]. Additionally, the SiC layer is susceptible to attack by palladium (one of the fission products), which can corrode the inner surface of the $\mathrm{SiC}$ layer and potentially compromise the retention of fission products [4]. Because of these limitations, a variation on the standard TRISO fuel design was proposed in which a zirconium carbide $(\mathrm{ZrC})$ layer would be used in place of the $\mathrm{SiC}$ layer [5].

Because of its intended use as the load-bearing layer in TRISO fuel for a VHTR, the response of $\mathrm{ZrC}$ to radiation damage must be understood. A number of investigations into the microstructural changes of $\mathrm{ZrC}$ under irradiation have been carried out in the past. Gan, et al. [6] conducted in situ irradiations of $\mathrm{ZrC}_{1.01}$ up to 10 and $30 \mathrm{dpa}$ at room temperature and 10 and $70 \mathrm{dpa}$ at $800^{\circ} \mathrm{C}$ using the Intermediate Voltage Electron Microscope (IVEM). A high density of black-dot defects was found at room temperature and dislocation segments were observed at $800^{\circ} \mathrm{C}$. Bulk ion irradiations of $\mathrm{ZrC}$ were performed by Yang, et al. [7] using $2.6 \mathrm{MeV}$ protons to 0.7 and $1.5 \mathrm{dpa}$ at $800^{\circ} \mathrm{C}$ who observed the formation of Frank loops, and by Gosset, et al. [8] using $4 \mathrm{MeV}$ Au ions at room 
temperature who found a high density of small defects which evolved into a dense dislocation network as the dose increased. Neutron irradiations were carried out by Snead, et al. [9] using the High Flux Isotope Reactor to fast neutron fluences of $0.8-9.38 \times 10^{25} \mathrm{~N} /\left(\mathrm{m}^{2} \mathrm{~s}\right)$ at temperatures ranging from $635-1496{ }^{\circ} \mathrm{C}$. The neutron irradiations resulted in the formation of dislocation loops which transitioned in nature from Frank to prismatic loops at higher temperatures. Some investigation into the effects of $\mathrm{ZrC}_{\mathrm{x}}$ stoichiometry on the irradiation response have been conducted using bulk proton irradiations at $800^{\circ} \mathrm{C}$ to $1-3 \mathrm{dpa}$ [10] and $1125^{\circ} \mathrm{C}$ to $2 \mathrm{dpa}$ [11]. However, there has been no systematic investigation into the effect of temperature on the accumulation of radiation damage in

$40 \mathrm{ZrC}$, and no irradiations have been performed at cryogenic temperatures where athermal reactions can be studied. Additionally, understanding of the effects of $\mathrm{ZrC}$ stoichiometry on radiation damage is limited with respect to irradiation temperature and dose.

This research is aimed at reaching a greater understanding of the fundamen${ }_{45}$ tal irradiation response of $\mathrm{ZrC}$. To further this goal, irradiations were carried out on $\mathrm{ZrC}_{\mathrm{x}}$ using $1 \mathrm{MeV} \mathrm{Kr}^{2+}$ ions while the evolution of the microstructure was simultaneously investigated using transmission electron microscopy (TEM). A range of irradiation temperatures were used, from cryogenic temperatures at which defects should have minimal mobility to high temperatures where the defects can move to form larger clusters. The irradiation temperature was systematically varied to determine its detailed effect on defect kinetics. Samples of two different stoichiometries were prepared and irradiated to determine the effect of stoichiometry on microstructural evolution under irradiation. Because the experiments were conducted in situ, the microstructure could be continuously followed, allowing for the direct observation of defect accumulation mechanisms as they occurred and more detailed inferences on the mechanisms. Finally, the effects of pre-existing microstructure, such as dislocations and the sample surface, on damage accumulation were investigated. 


\section{Experiment}

The $\mathrm{ZrC}_{\mathrm{x}}$ was received as rods with $3 \mathrm{~mm}$ diameter and approximately $3 \mathrm{~cm}$ length. Samples were prepared by first sectioning the rod into disks using a low-speed saw with metal-bonded diamond wafering blade. The disks were then thinned to approximately $200 \mu \mathrm{m}$ thickness using successive grinding and polishing steps with 400, 600 and 800 grit $\mathrm{SiC}$ abrasive disks. Finally, the samples were prepared for transmission electron microscope (TEM) examination by electrolytic polishing using a Struers TenuPol-5. The electropolishing settings are provided in Table 1. The samples were removed and rinsed in methanol and ethanol immediately after electropolishing and stored in ethanol until their use.

This sample preparation method produced samples with a "clean" microstructure, featuring a single $\mathrm{ZrC}_{\mathrm{x}}$ phase with large grains and a low dislocation density before irradiation. Typically only a single grain was visible in the electrontransparent region of the TEM samples. Figure 1 shows a low magnification dark-field TEM image taken from $\mathrm{ZrC}_{0.9}$ before irradiation which demonstrates the features described above. Because the microstructure was relatively free of features, a dislocation was typically chosen as a marker to be followed throughout an experiment.

\subsection{IVEM Irradiations}

85 Irradiation experiments were conducted at the Intermediate Voltage Electron Microscope (IVEM) facility at Argonne National Laboratory [13]. The IVEM consists of a Hitachi H-9000NAR transmission electron microscope (TEM) interfaced with an ion accelerator to allow for concurrent ion irradiation and TEM 
examination of a sample. This capability makes it possible to continuously follow the evolution of the microstructure due to irradiation in real time. Dynamic processes such as defect creation, annihilation and interaction can be observed, and the IVEM is equipped to record video of the microstructure evolution during irradiation for later analysis.

The irradiations in this study were performed using $1 \mathrm{MeV} \mathrm{Kr}^{2+}$ ions at 95 a flux of $6.25 \times 10^{15}$ ions $/\left(\mathrm{m}^{2} \mathrm{~s}\right)$. $1 \mathrm{MeV} \mathrm{Kr}$ ions were chosen because a high dose rate can be achieved, the damage profile does not vary greatly in a TEM thin foil and the majority of ions pass completely through the thin foil. The equivalent dose in displacements per atom (dpa) was calculated using the Stopping and Range of Ions in Matter (SRIM) program [14]. The input parameters used for the SRIM calculation are provided in Table 2. A simulation involving 10,000 ions resulted in an average of $2393 \pm 48$ displacements per ion within the thin foil, assumed to be $100 \mathrm{~nm}$ thick. ${ }^{1}$ This is equivalent to a dose rate of $2.1 \times 10^{-3} \mathrm{dpa} / \mathrm{s}$ when averaged over the whole sample. For the purposes of reporting the dose in this study, 1 dpa is equivalent to a measured ion fluence of $3.0 \times 10^{18}$ ions $/ \mathrm{m}^{2}$. By assuming surface binding energies equal to one-half the displacement energies, SRIM calculates a sputtering yield of 2.036 atoms/ion, or an equivalent removal rate of approximately $8.5 \times 10^{-2} \mathrm{~nm} /$ dpa. Even at the maximum dose of $16.4 \mathrm{dpa}$, only $1.4 \mathrm{~nm}$ of material is removed from the nominally $100 \mathrm{~nm}$ thick foil.

Irradiations were conducted over a wide range of temperatures, ranging from $20 \mathrm{~K}$ to $1073 \mathrm{~K}$. The full range of irradiation conditions is listed in Table 3. During the experiments, samples were heated or cooled to the desired temperature and then pre-irradiation images were acquired. Temperatures below room temperature were achieved using a double-tilt, liquid helium cooled cryo-holder.

\footnotetext{
${ }^{1}$ It should be noted that the damage rate is $1936 \pm 36$ displacements per ion when using the "Ion Distribution and Quick Calculation of Damage" option in SRIM as reccomended by Stoller, et al. [15]. The "Full Cascade" option was chosen instead because the damage model used for the quick calculation does not explicitly treat multi-element materials.
} 

extinction distance was calculated using

$$
\xi_{g}=\frac{\pi V_{c} \cos \theta_{B}}{\lambda F_{g}}
$$

where $V_{c}$ is the volume of the unit cell, $\theta_{B}$ is the Bragg angle, $\lambda$ is the electron 
wavelength, and $F_{g}$ is the structure factor [17]. The structure factor for $\mathrm{ZrC}$ is 145 given by

$$
F_{g}= \begin{cases}4\left(f_{Z r}+f_{C}\right) & \text { if } \mathrm{h}, \mathrm{k}, \text { and } \mathrm{l} \text { are all even } \\ 4\left(f_{Z r}-f_{C}\right) & \text { if } \mathrm{h}, \mathrm{k}, \text { and } \mathrm{l} \text { are all odd } \\ 0 & \text { otherwise }\end{cases}
$$

where $f_{Z r}$ and $f_{C}$ are the atomic scattering amplitudes for $\mathrm{Zr}$ and $\mathrm{C}$, and $\mathrm{h}, \mathrm{k}$ and $l$ are the indices of atomic planes. Using the atomic scattering amplitudes in [18], the extinction distance is calculated to be $54 \mathrm{~nm}$ for $\mathrm{g}=220 \mathrm{in} \mathrm{ZrC}$ with a lattice parameter $a_{0}=0.47 \mathrm{~nm}$ while operating a TEM at $200 \mathrm{keV}$. The extinction distance was also measured by convergent beam electron diffraction (CBED) as outlined by Kelly, et al. [19]. Operating the TEM at $200 \mathrm{keV}$, the extinction distance was found to be $56.6 \mathrm{~nm}$, approximately $5 \%$ larger than the calculated value. The calculated extinction distance was used when determining sample thickness.

\section{Results}

The experimental results are discussed in this section and are organized by irradiation temperature. Additional observations are then discussed separately.

\subsection{Dose evolution of irradiated microstructure}

During irradiation at a temperature of $50 \mathrm{~K}$, no damage was seen up to a dose of 0.8 dpa when small, black-dot defects started to appear. The density of this black-dot damage increased swiftly with dose up to $3.3-4.9 \mathrm{dpa}$, at which point the rate of damage accumulation appeared to decrease. Representative images of the damage progression are shown in Figure 2. The initial defects seen at $0.8 \mathrm{dpa}$ are arrowed. The defect density does not appreciably change between 8.2 and 16.4 dpa. The defects, once created, were stable (no defects disappeared once created) and immobile during irradiation, such that the defect density simply increased to saturation. This is in contrast to other experiments, such as the in situ irradiation of alloy NF616, in which a dynamic equilibrium 
was observed with defects appearing and disappearing when the ion beam was

observed, even after irradiating to 16.4 dpa at $50 \mathrm{~K}$ and to 8.2 dpa at $20 \mathrm{~K}$. This indicates a high resistance to amorphization, which agrees with theoretical considerations as outlined by Zheng, et al., including high antisite defect energies, over-constrained topology and high concentration of carbon vacancies [22]. loops with diameters up to approximately $30 \mathrm{~nm}$ (as shown in Figure 5). Images acquired near a $\langle 220\rangle$ zone axis show edge on loops consistent with $\{111\}$ and $\{220\}$ habit planes. These habit planes could indicate the presence of Frank 
loops and prismatic loops, both observed to result from neutron irradiation [9]. The microstructure continued to visibly coarsen until 6.6 - $9.9 \mathrm{dpa}$, beyond which dose little change in the microstructure was observed. At the end of the irradiation the microstructure showed a tangled dislocation structure, which could result from the projected image of overlapping dislocation loops.

During irradiation at $1073 \mathrm{~K}$, while no apparent long-range motion of visible defects was observed, interaction of closely spaced defects, possibly by defect strain-field interactions, was observed after high defect densities were achieved, i.e. greater than 1.6 dpa. A series of images captured from the video recorded between 1.6 and $3.3 \mathrm{dpa}$ is shown in Figure 5. These images, showing dose steps of $0.5 \mathrm{dpa}$, are centered on an area which initially contained only black-dot damage or small dislocation loops of similar size at 1.6 dpa. A larger dislocation loop with non-circular shape began to form by $2.3 \mathrm{dpa}$. The loop then grew and became more circular as the dose was increased to $3.3 \mathrm{dpa}$. Based on the video, it is likely that the loop formed and grew by coalescence of smaller defects. Because this defect coalescence and coarsening is only observed at higher temperatures, it likely results from thermally activated motion of defect clusters.

It is interesting to directly compare the microstructures resulting from irradiation to $8.2 \mathrm{dpa}$ at different temperatures, as shown in Figure 6. During irradiation at $300 \mathrm{~K}$, the microstructure was dominated by black-dot defects. In contrast, the small loops showing double-arc contrast also seen at $673 \mathrm{~K}$ were observed at $473 \mathrm{~K}$. At higher irradiation temperatures, defect size increased further, such that at $873 \mathrm{~K}$ larger loops appeared, both with and without double-arc contrast. The microstructure coarsened further during irradiations conducted at $973 \mathrm{~K}$ and at $1073 \mathrm{~K}$. At these irradiation temperatures the microstructure consisted of dislocation loops and tangled dislocation segments, which may result from the projection of overlapping dislocation loops visualized through the foil thickness. To summarize, higher irradiation temperatures resulted in larger defects with coarser microstructure, likely as a result of increased defect mobility. 


\subsection{Mean defect diameter and density}

Figure 7 shows the mean defect diameter measured as a function of dose for three different temperatures. ${ }^{2}$ The series of measurements at each temperature were made from three single experiments. In general, defects were larger at the temperature region where the defect clusters are mobile and can interact

\footnotetext{
${ }^{2}$ When "defect size" or "defect diameter" is referenced, it refers to a measurement of the contrast produced by the defect while using a given imaging condition.
} 
with the foil surface. To assess this effect, the microstructure formed at different foil thicknesses was studied by examining a wedge-shaped foil of $\mathrm{ZrC}_{0.9}$ irradiated at $1073 \mathrm{~K}$ at various distances from the foil edge. The irradiated microstructure was observed to strongly depend on the foil thickness. Figure 9 shows a bright-field micrograph acquired near the sample edge after irradiation to $6.6 \mathrm{dpa}$ at $1073 \mathrm{~K}$. A defect-denuded zone is observed at the edge of the sample, the thinnest part of the sample. With increasing thickness, first black-dot defects are seen and then larger, resolvable dislocation loops are observed. A similar dependence of irradiated microstructure on foil thickness was also observed during irradiations performed at $973 \mathrm{~K}$ and $873 \mathrm{~K}$. This variation of the irradiated microstructure likely resulted from the loss of defects at the foil surface. In the thinner region of the foil, the depth from where defects can migrate to the surface can be greater than the foil thickness, in which case no defect accumulation can occur. In the thicker region of the foil, defect motion can result in the formation of larger defects, such that the defect size increases with foil thickness, until it approaches that seen during bulk ion irradiation (i.e. far from the foil surface). Figure 10 illustrates the expected dependence of microstructure on foil thickness. Because defect motion is thermally activated, the dependence defect density on foil thickness was not observed at low temperatures.

\subsection{Comparison of $\operatorname{ZrC}_{0.8}$ and $\mathrm{ZrC}_{0.9}$ irradiated microstructure}

Both $\mathrm{ZrC}_{0.8}$ and $\mathrm{ZrC}_{0.9}$ were irradiated at several temperatures in this work. For example, after irradiation at $473 \mathrm{~K}$, both $\mathrm{ZrC}$ compositions showed a high density of black-dot defects, while at $1073 \mathrm{~K}$, both showed a coarse microstructure with loops and tangled dislocation segments. This was true of the microstructures resulting from irradiations at all the temperatures listed in Table 3. We conclude that the irradiated microstructures of $\mathrm{ZrC}_{0.8}$ and $\mathrm{ZrC}_{0.9}$ are similar over the range of temperatures in this study.

This lack of dependence on $\mathrm{ZrC}$ stoichiometry can be understood in a straightforward manner. Because the stoichiometry variation in $\mathrm{ZrC}$ is accommodated 
by vacancies on the carbon sub-lattice [25], it is likely that the carbon sub-lattice does not have a strong influence on the development of radiation damage in $\mathrm{ZrC}$. It can be reasoned that, for $\mathrm{ZrC}_{0.8}$ and $\mathrm{ZrC}_{0.9}$ with $10 \%$ and $20 \%$ vacancies on the carbon sub-lattice, one could expect that if the nucleation and growth of defect clusters were controlled by carbon vacancies, the accumulation of defects during irradiation would vary between the two. Additionally, the barriers for carbon and zirconium vacancy migration $(4.41 \mathrm{eV}$ and $5.44 \mathrm{eV}$ respectively), as reported by Zheng, et al. [22], are quite high and would not activate in the temperature range studied. Furthermore, the antisite defect energy is very high (greater than $11 \mathrm{eV}[26]$ ) so that the $\mathrm{C}$ and $\mathrm{Zr}$ sub-lattices are essentially independent of each other. Finally, with $10 \%$ and $20 \%$ carbon vacancies, it is difficult for irradiation generated carbon interstitials to survive recombination. This indicates that the likely defect controlling the microstructure evolution in $\mathrm{ZrC}$ is zirconium interstitials and interstitial clusters.

\subsection{Diffraction pattern changes during irradiation}

As mentioned in Section 2.2, diffraction patterns were systematically recorded from the imaged regions at selected doses during irradiation. While the $\mathrm{ZrC}$ lattice parameter did not measurably change, extra diffraction rings and spots developed during all irradiations except those completed at $300 \mathrm{~K}$ and $473 \mathrm{~K}$. The diffraction rings appeared around 1.6 - 3.3 dpa and intensified as the dose increased. Figure 11 shows two examples acquired during irradiations at $50 \mathrm{~K}$ and 1073 K. Complete diffraction rings developed at low temperatures and more textured rings or spot patterns developed at higher temperatures (approximately $873 \mathrm{~K}$ and up). The d-spacings associated with the low temperature rings and the high temperature textured rings and spots, relative the $\mathrm{ZrC}$ lattice parameter, were the same. Figure 12 shows a bright-field/dark-field pair acquired after irradiating to $16.4 \mathrm{dpa}$ at $50 \mathrm{~K}$; the dark-field image was formed using a diffraction ring that developed during irradiation. The features observed in the dark-field image appear to be equiaxed and correspond to the larger dark spots observed in the bright-field image. 
The diffraction rings and spots that appeared during irradiation were indexed and were consistent with a face-centered cubic (FCC) lattice with a measured lattice parameter of $0.506 \mathrm{~nm}$, or $8 \%$ larger than the $\mathrm{ZrC}$ lattice. Depending on the particular diffraction pattern, up to seven diffraction rings were indexed. These observations are similar to those made by Gan, et al., who, during in situ irradiation at the IVEM, also observed FCC diffraction rings with a lattice parameter $8 \%$ larger than $\mathrm{ZrC}$ [6]. Additionally, Gosset, et al. observed diffraction rings after bulk ion irradiation of $\mathrm{ZrC}$ at room temperature. The authors in that study attributed the rings to a zirconia phase which formed on the surface of samples that had been pre-thinned before irradiation [8].

Although the lattice parameter of $0.506 \mathrm{~nm}$ is close to that of the zirconia high temperature phase ${ }^{3}$, attributing these diffraction rings to zirconia has a few difficulties as it is not clear how oxidation could occur at $20 \mathrm{~K}$ and also because $\mathrm{ZrO}_{2}$ is monoclinic (or tetragonal) at the temperatures studied. The size of the features observed in dark-field suggests that these could be very small precipitates of a second phase which are severely distorted while maintaining coherency with the substrate.

In addition to the diffraction rings, streaks developed in the diffraction pattern during irradiations at $300 \mathrm{~K}$ and above. The streaks appeared to be more intense at higher temperatures, but no systematic diffraction patterns were recorded to directly compare at different temperatures. The streaks appeared between either $\{111\}$ and $\{220\}$ reflections or $\{200\}$ and $\{111\}$ reflections when the sample was tilted near a $\langle 220\rangle$ zone axis. In both cases, the streaks were in a $\langle 111\rangle$ direction. The streak orientation indicates a relaxation of the diffraction condition in the $\langle 111\rangle$ direction, and could possibly be due to presence of stacking faults associated with Frank loops, such as those observed by Yang, et al. using rel-rod dark-field imaging [7].

\footnotetext{
${ }^{3}$ The cubic phase of zirconia has a lattice parameter of $0.5128 \mathrm{~nm}$ (ICDD \# 49-1642).
} 


\section{Discussion}

The response of $\mathrm{ZrC}$ to ion irradiation can be separated into two different regimes. At lower temperatures (approximately $300 \mathrm{~K}$ and below), the accumulation of radiation damage in the form of black dot defects is likely controlled by athermal processes leading to the similar damage structures observed over this temperature range. Above these temperatures, however, a dependence of the irradiated microstructure on irradiation temperature is observed, whereby high irradiation temperatures result in increased defect diameter and decreased defect density. As the defect cluster diameter increases, individual dislocation loops can be discerned. In this temperature range it is likely that the thermally activated motion of defects has increased to the point that it supersedes the athermal processes occurring at low temperatures.

We can infer the processes involved in the thermally activated defect growth regime. Because calculations of defect migration energies have shown that there are high barriers to migration for both carbon and zirconium vacancies [22], these defects would not be mobile at the temperatures used in these experiments. Since this means that vacancies cannot agglomerate, this explains why no voids were observed in this study as there would be no mechanism for void growth. Calculations indicate that thermally activated mobility of both carbon and zirconium interstitials would be possible within the temperature range of these experiments. However, due to the high concentration of structural carbon vacancies in the sub-stoichiometric $\mathrm{ZrC}_{\mathrm{x}}$ compound, carbon interstitials would recombine quickly, and it is difficult to imagine a situation in which they could accumulate and form defect clusters. Therefore, the most likely candidate for the formation and growth of defect clusters is zirconium interstitials.

The results from this experiment agree well with previous in situ irradiation experiments at room temperature and $800^{\circ} \mathrm{C}$, during which black dot defects formed at room temperature and dislocation segments were observed after irradiating at $800^{\circ} \mathrm{C}[6]$. Examination after bulk proton irradiations at $800^{\circ} \mathrm{C}$ to 0.7 and 1.5 dpa showed that both defect diameter and density increased with dose, 
matching the present results for that dose range [7]. Bulk proton irradiations performed at $800^{\circ} \mathrm{C}$ [10], however, resulted in defect densities that were an order of magnitude lower and defect diameters that were twice as large for $\mathrm{ZrC}_{0.9}$ than those found in the present study. A couple of differences between the two experiments may account for the differences in results. These experiments were carried out with a dose rate of $4.7 \times 10^{-5} \mathrm{dpa} / \mathrm{s}$, almost 30 times lower than used in this study when calculated using the same displacement energies for Zr and C. It is possible that the higher dose rate in this study resulted in a saturation of a higher number of smaller defects, because there was relatively less time for defect migration which limited coalescence and growth.

A bulk proton irradiation study of $\mathrm{ZrC}_{\mathrm{x}}$ was performed at $1125^{\circ} \mathrm{C}$ to $2 \mathrm{dpa}$ by Yang et al. [11] to investigate the effects of sample stoichiometry. The results showed that the dislocation diameters varied little for the sub-stoichiometric material, which agrees well with the observations made in these experiments. However, defect size increased with carbon content in the hyper-stoichiometric material. In addition, it was noted that there was increased loop density near graphite phases. While the weak dependence on carbon content for substoichiometric $\mathrm{ZrC}_{\mathrm{x}}$ is verified, it appears that other mechanisms for defect nucleation or growth may occur in the hyper-stoichiometric compound. This may be understood within the presently explained mechanisms in that the structural carbon vacancy concentration is lower in the hyper-stoichiometric compound. It is possible that the carbon vacancy concentration in the hyper-stoichiometric samples is low enough that carbon interstitials are able to contribute to the formation and growth of dislocation loops. Because carbon interstitials are more mobile than zirconium interstitials [22], they are able to increase the growth rate of dislocation loops. Graphite phases may locally act as a source for additional carbon atoms during irradiation which would explain the increased defect density near these phases.

The comparison of the results of this study to those obtained from neutron irradiation are of great importance for the use of $\mathrm{ZrC}$ in nuclear reactors. ${ }_{05}$ The work performed by Snead, et. al [9] included, among other things, TEM 
defect anlysis of $\mathrm{ZrC}_{0.87}$ after irradiation in the High Flux Isotope Reactor (HFIR). While these irradiations were performed at temperatures ranging from $635-1480{ }^{\circ} \mathrm{C}(908-1753 \mathrm{~K})$, it does overlap the highest irradiation temperatures of the present study which had a maximum irradiation temperature $1023{ }^{\circ} \mathrm{C}(1296 \mathrm{~K})$, and prismatic loops had formed at $1496{ }^{\circ} \mathrm{C}(1769 \mathrm{~K})$. These are in agreement with the edge-on loops with $\{111\}$ and $\{220\}$ habit planes observed after in situ irradiation at $1073 \mathrm{~K}$. Also in agreement with the present study, average loop diameter tended to increase, and loop density tended to decrease, with increased irradiation temperature during neutron irradiation. Additionally, the average defect diameter and defect density after neutron irradiation at $660{ }^{\circ} \mathrm{C}(933 \mathrm{~K})$, approximately $4 \mathrm{~nm}$ and $3 \times 10^{22} \mathrm{~m}^{-3}$, respectively, are similar to those presented in Figures 7 and 8; a direct comparison of values is not possible becuase the imaging condition is not clearly stated in [9].

420 velop after nuetron irradiation vs. in situ ion irradiation as a result of, among other things, thin film effects and differences in dose rate. During in situ ion irradiation, such as used in this study, a thin foil with thickness on the order of a few hundred nanometers or less is irradiated. With this geometry, there 425 is a large concentration of free surface which can act as a sink for defects and supress the concentration of freely migrating defect clusters. This could in turn supress defect nucleation and growth resulting in lower visible defect density and smaller visible defects. The thin film effect was clearly observed during these experiments (see Figure 9), where a defect-denuded zone developed in the thinnest regions of the sample.

The dose rate during these in situ ion irradiations, $2.1 \times 10^{-3} \mathrm{dpa} / \mathrm{s}$, is several orders of magnitude greater than during neutron irradiation. It is thought that changes to one irradiation variable can be accomodated by changes to another variable such that the desired irradiation feature remains unchanged [27]. ${ }_{435}$ Specifically, a higher dose rate can be accomodated by irradiating at a higher temperature, or conducting an irradiation at increased dose rate is equivalent 
to holding the dose rate constant but decreasing the irradiation temperature. Becuase of the observed trends of loops with temeprature, it would be expected that irradiating at a higher dose rate in $\mathrm{ZrC}$ would result in smaller average loop diameter and higher loop density.

\section{Conclusion}

In situ ion irradiation using the Intermediate Voltage Electron Microscope (IVEM) at Argonne National Laboratory was used to study the microstructure evolution of $\mathrm{ZrC}_{\mathrm{x}}$ under irradiation. Irradiations were carried out using $1 \mathrm{MeV}$

$\mathrm{Kr}$ ions up to doses of $16.4 \mathrm{dpa}$, or $5 \times 10^{19}$ ions $/ \mathrm{m}^{2}$, at temperatures ranging from $20-1073 \mathrm{~K}$. The detailed conclusions are as follows:

1. During low temperature irradiation (at $300 \mathrm{~K}$ and below), damage was observed in the form of small defect clusters, or "black-dot" damage. The damage appeared after a threshold dose and increased gradually with dose until saturation after several dpa. Once visible defects were created, they were stable and neither moved nor were destroyed during the remainder of the experiment.

2. In the high temperature regime (at $873 \mathrm{~K}$ and above), although visible defects did not appear to migrate thermally, interaction of closely spaced defects was observed which resulted in microstructure coarsening through defect coalescence.

3. In the high temperature regime, the foil surface was found to act as a strong sink for defects as demonstrated by the defect-denuded zone and evolution of defect diameter with foil thickness near the sample edge.

4. No void formation or amorphization were observed at any of the temperatures studied.

5. The irradiated microstructure of $\mathrm{ZrC}_{\mathrm{x}}$ was not observed to vary significantly with composition in the range of $\mathrm{x}=0.8-0.9$.

6. Diffraction rings formed during all irradiations except at $300 \mathrm{~K}$ and $473 \mathrm{~K}$ and were more highly oriented, or textured, at higher temperatures. The 
ring pattern was indexed and was consistent with an FCC lattice with a lattice parameter $8 \%$ larger than that of $\mathrm{ZrC}$.

7. Up to the doses studied, the irradiated microstructure of $\mathrm{ZrC}$ appears to be reasonably stable with gradual changes up to 5-7 dpa where it approached saturation. Irradiations to higher doses will be necessary to further explore the stability of $\mathrm{ZrC}$ with respect to irradiation.

8. Zirconium interstitials and interstitial clusters are likely dominant in the formation and growth of visible defect clusters in sub-stoichiometric $\mathrm{ZrC}$.

\section{Acknowledgments}

This work was funded by the U.S. Department of Energy's Nuclear Engineering University Program project number 10-679. The electron microscopy with in situ ion irradiation was accomplished at Argonne National Laboratory at the IVEM-Tandem Facility, a U.S. Department of Energy Facility funded by the DOE Office of Nuclear Energy, operated under Contract No. DE-AC0206CH11357 by UChicago Argonne, LLC. We thank Pete Baldo and Ed Ryan of Argonne National Laboratory for their invaluable assistance in carrying out the irradiations. We also thank Ming-Jie Zheng, Izabela Szlufarska, Dane Morgan and Yina Huang for their insights and discussions.

\section{References}

[1] Generation IV International Forum and U.S. DOE NERAC, GIF-002-00, 2002.

[2] R. Morris, D. Petti, D. Powers, B. Boyack, NUREG-6844, U.S. Nuclear Regulatory Commission, 2004.

[3] D. T. Goodin, Journal of the American Ceramic Society 65 (1982) 238-242. doi:10.1111/j.1151-2916.1982.tb10425.x. 
[4] K. Minato, T. Ogawa, S. Kashimura, K. Fukuda, M. Shimizu, Y. Tayama, I. Takahashi, Journal of Nuclear Materials 172 (1990) 184-196. doi:10. 1016/0022-3115(90) 90437-R.

[5] P. Wagner, LA-6984, Los Alamos Scientific Laboratory, 1977. doi:10.2172/ 5361609.

[6] J. Gan, M. K. Meyer, R. C. Birtcher, T. R. Allen, Journal of ASTM International 3 (2006) 1-7. doi:10.1520/JAI12376.

[7] Y. Yang, C. A. Dickerson, H. Swoboda, B. Miller, T. R. Allen, Journal of Nuclear Materials 378 (2008) 341-348. doi:10.1016/j.jnucmat.2008.06. 042.

[8] D. Gosset, M. Dollé, D. Simeone, G. Baldinozzi, L. Thomé, Journal of Nuclear Materials 373 (2008) 123-129. doi:10.1016/j.jnucmat.2007.05. 034.

[9] L. L. Snead, Y. Katoh, S. Kondo, Journal of Nuclear Materials 399 (2010) 200-207. doi:10.1016/j.jnucmat.2010.01.020.

[10] Y. Huang, B. Maier, T. Allen, Nuclear Engineering and Design 277 (2014) 55-63. doi:10.1016/j.nucengdes.2014.06.001.

[11] Y. Yang, W. Y. Lo, C. Dickerson, T. R. Allen, Journal of Nuclear Materials 454 (2014) 130-135. doi:10.1016/j.jnucmat.2014.07.071.

[12] W. Mackie, C. Hinrichs, Journal of Crystal Growth 87 (1988) 101-106. doi:10.1016/0022-0248(88)90347-8.

[13] C. W. Allen, L. L. Funk, E. A. Ryan, in: MRS Proceedings, volume 396, Cambridge Univ Press, p. 641. doi:10.1557/PROC-396-641.

[14] J. F. Ziegler, M. Ziegler, J. Biersack, Nuclear Instruments and Methods in Physics Research Section B: Beam Interactions with Materials and Atoms 268 (2010) 1818-1823. doi:10.1016/j.nimb.2010.02.091. 
[15] R. E. Stoller, M. B. Toloczko, G. S. Was, A. G. Certain, S. Dwaraknath, F. A. Garner, Nuclear Instruments and Methods in Physics Research Section B: Beam Interactions with Materials and Atoms 310 (2013) 75-80. doi:10.1016/j.nimb.2013.05.008.

[16] C. A. Schneider, W. S. Rasband, K. W. Eliceiri, Nature Methods 9 (2012) 671-675. doi:10.1038/nmeth.2089.

[17] D. B. Williams, C. B. Carter, Transmission Electron Microscopy, Springer, 2009. doi:10.1007/978-0-387-76501-3_1.

[18] E. Prince, International Tables for Crystallography: Vol. C: Mathematical, Physical and Chemical Tables Third Edition, Wiley, Hoboken, 2004.

[19] P. Kelly, A. Jostsons, R. Blake, J. Napier, Physica Status Solidi A 31 (1975) 771-780. doi:10.1002/pssa.2210310251.

[20] C. Topbasi, A. T. Motta, M. A. Kirk, Journal of Nuclear Materials 425 (2012) 48-53. doi:10.1016/j.jnucmat.2011.08.046.

[21] A. T. Motta, Journal of Nuclear Materials 244 (1997) 227-250. doi:10. 1016/S0022-3115(96)00740-4.

[22] M. J. Zheng, I. Szlufarska, D. Morgan, Journal of Nuclear Materials 457 (2015) 343-351. doi:10.1016/j.jnucmat.2014.11.059.

[23] M. Li, M. Kirk, P. Baldo, D. Xu, B. Wirth, Philosophical Magazine 92 (2012) 2048-2078. doi:10.1080/14786435.2012.662601.

[24] A. Motta, D. Olander, Acta Metallurgica et Materialia 38 (1990) 21752185. doi:10 .1016/0956-7151(90)90085-U.

[25] H. W. Hugosson, U. Jansson, B. Johansson, O. Eriksson, Chemical Physics Letters 333 (2001) 444-450. doi:10.1016/S0009-2614(00)01414-7.

[26] S. Kim, I. Szlufarska, D. Morgan, Journal of Applied Physics 107 (2010) 053521. doi:10.1063/1.3309765. 
[27] L. Mansur, Journal of Nuclear Materials 216 (1994) 97 - 123. doi:http: //dx.doi.org/10.1016/0022-3115(94)90009-4.

${ }_{545}$ [28] M. Zheng, D. Swaminathan, D. Morgan, I. Szlufarska, 2015. (unpublished). 


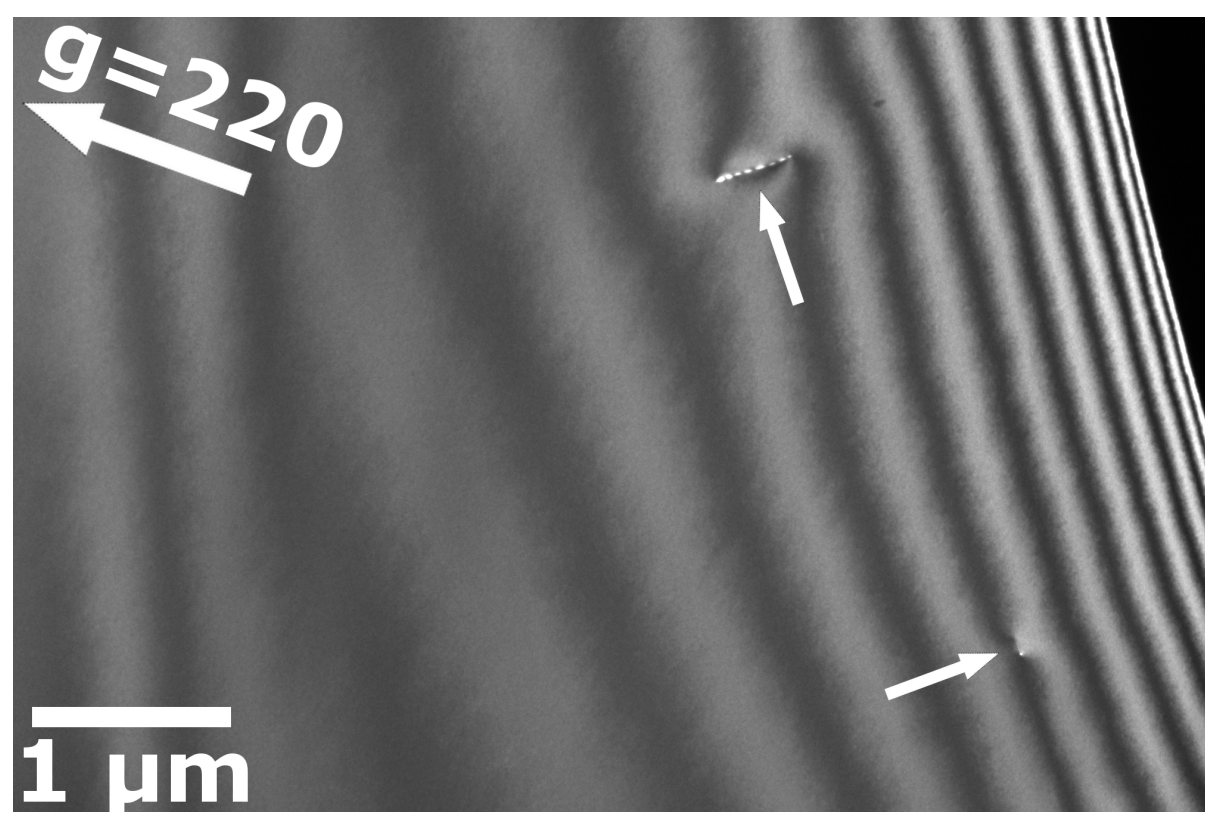

Figure 1: Dark-field TEM micrograph $(\mathrm{g}, 3 \mathrm{~g})$ of the unirradiated microstructure of $\mathrm{ZrC}_{0.9}$. Two dislocations present before irradiation are indicated by arrows. 


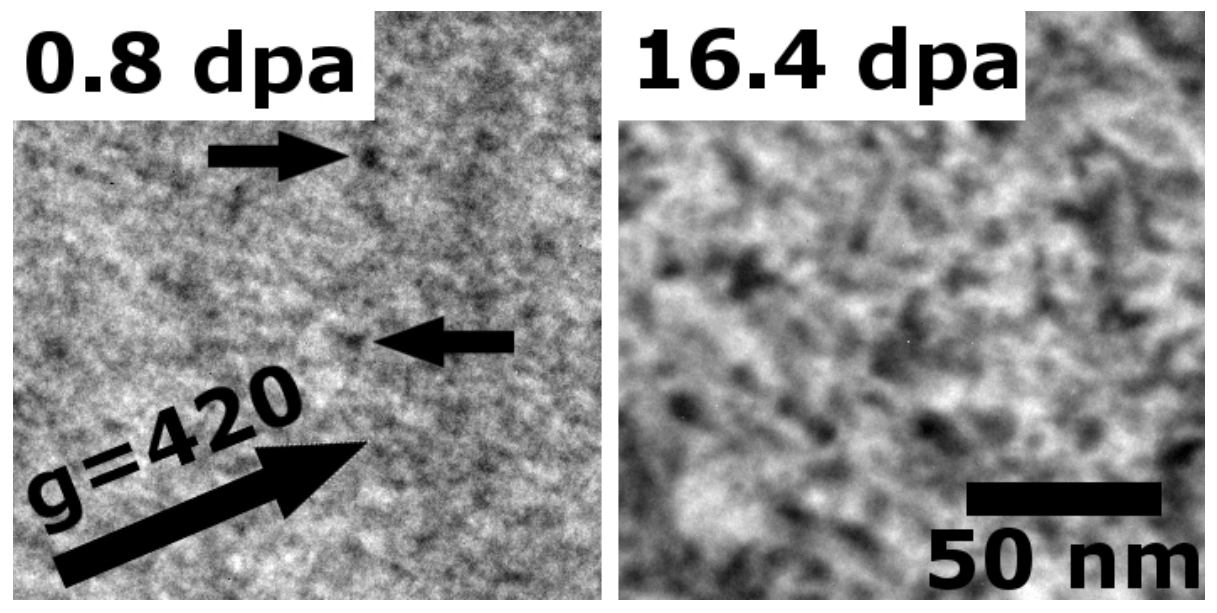

Figure 2: Bright-field TEM micrographs with $\mathrm{g}=420$ showing the dose evolution of irradiated microstructure of $\mathrm{ZrC}_{0.9}$ at $50 \mathrm{~K}$. Doses of 0.8 and $16.4 \mathrm{dpa}$ are shown. Small arrows point to examples of defects formed at $0.8 \mathrm{dpa}$.
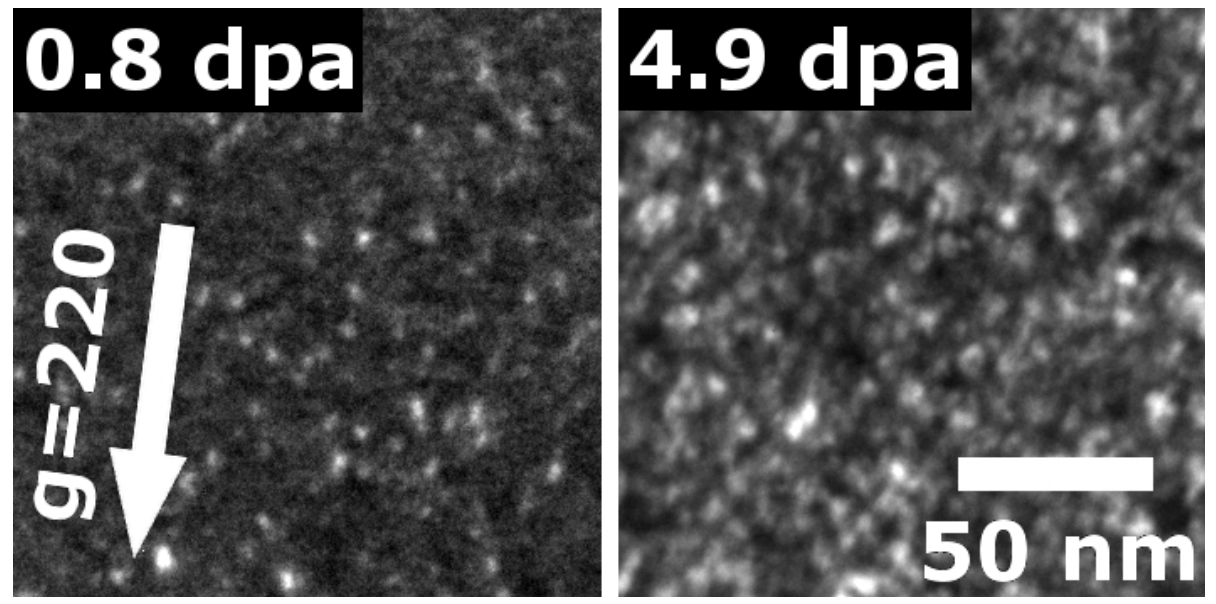

Figure 3: Dark-field TEM micrographs imaged with $\mathrm{g}=220(\mathrm{~g}, 3 \mathrm{~g})$ showing the dose evolution of the irradiated microstructure of $\mathrm{ZrC}_{0.9}$ at $673 \mathrm{~K}$ up to 4.9 dpa. 

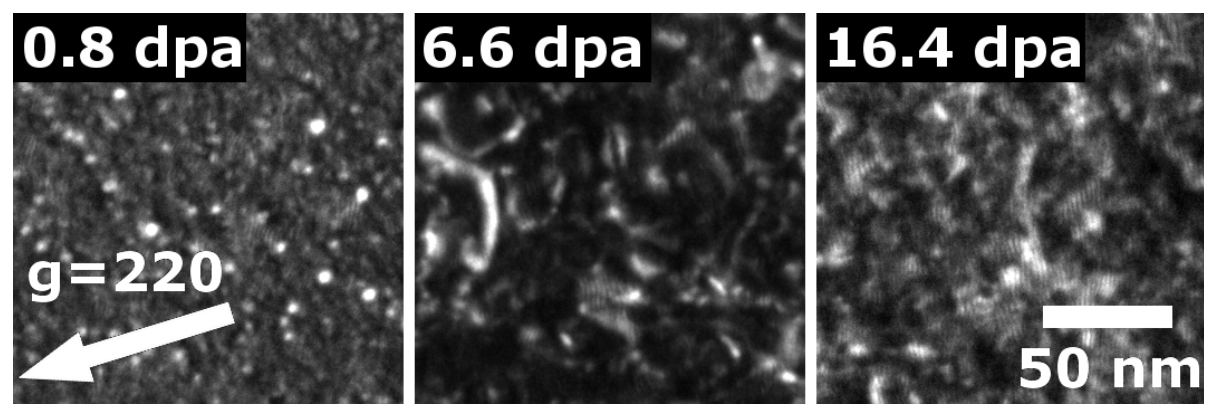

Figure 4: Dark-field TEM micrographs imaged with $\mathrm{g}=220(\mathrm{~g}, 3 \mathrm{~g})$ showing the dose evolution of irradiated microstructure of $\mathrm{ZrC}_{0.9}$ at $1073 \mathrm{~K}$. Coalescence of defects results in a coarse microstructure at this temperature. 

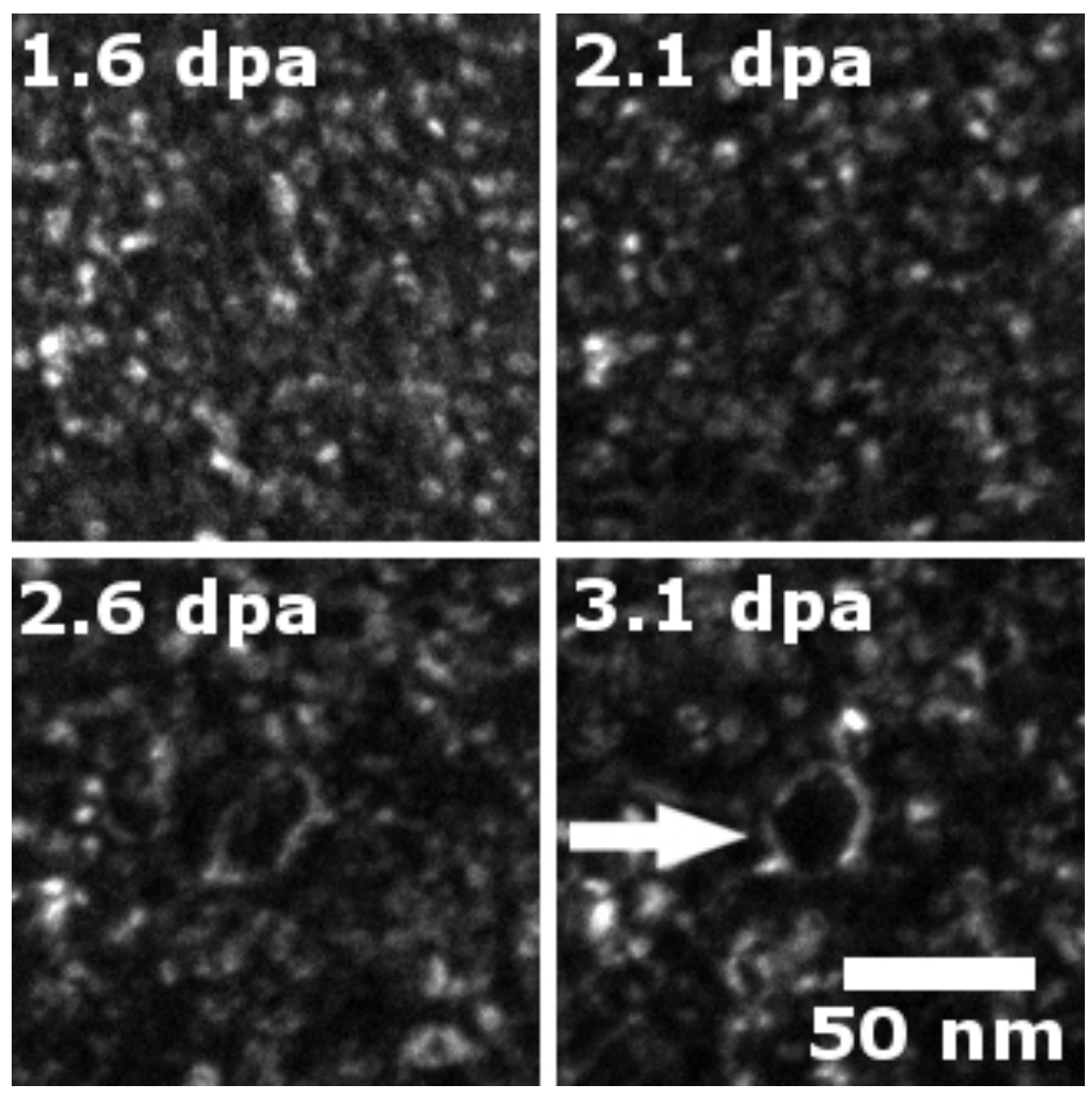

Figure 5: Several dark-field TEM images with $\mathrm{g}=220(\mathrm{~g}, 3 \mathrm{~g})$ captured from the video taken during the irradiation of $\mathrm{ZrC}_{0.9}$ between 1.6 and $3.3 \mathrm{dpa}$ showing the formation of a larger dislocation loop by defect coalescence. Images are shown in dose increments of $0.5 \mathrm{dpa}$, and an arrow at $3.1 \mathrm{dpa}$ indicates the dislocation loop of interest. 

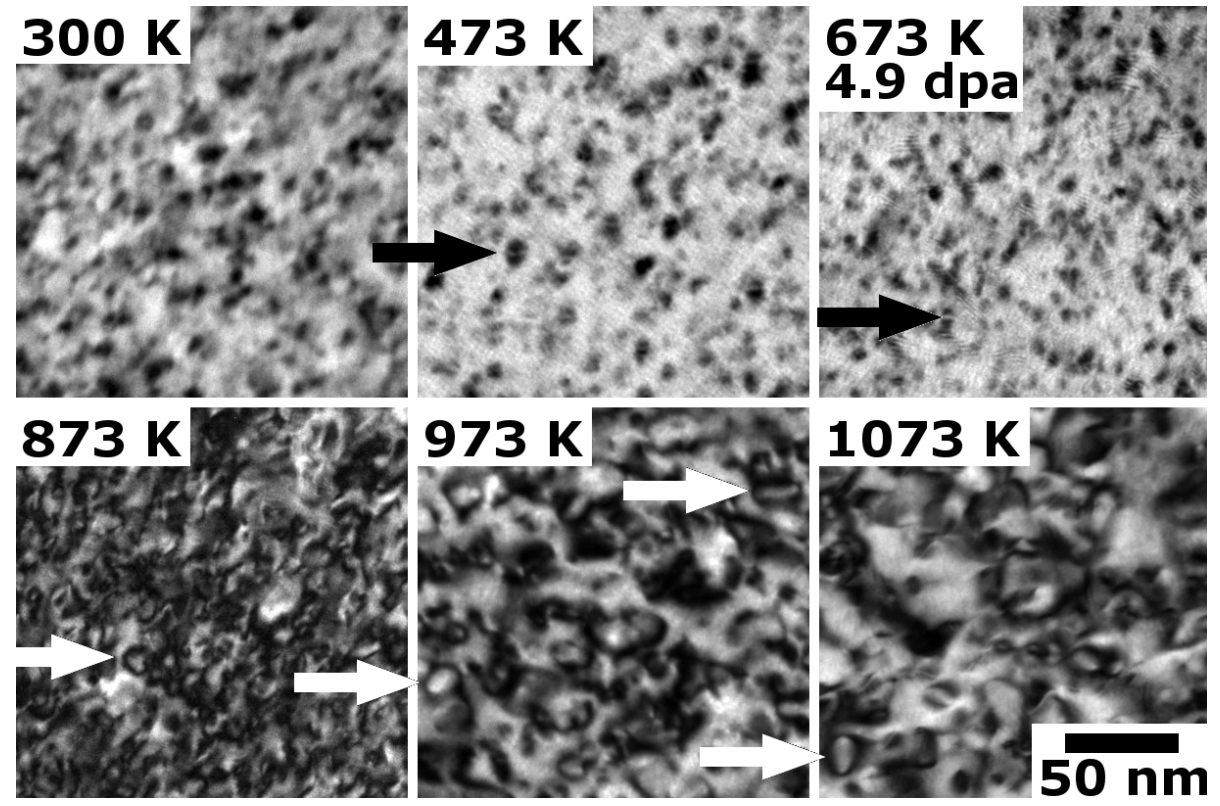

Figure 6: Bright-field images of the microstructures resulting from irradiating $\mathrm{ZrC}_{0.9}$ to $8.2 \mathrm{dpa}$ (except where noted at $673 \mathrm{~K}$ ) at temperatures ranging from $300-1073 \mathrm{~K}$. Dislocation loops with (black) and without (white) double-arc contrast are indicated by the arrows. 


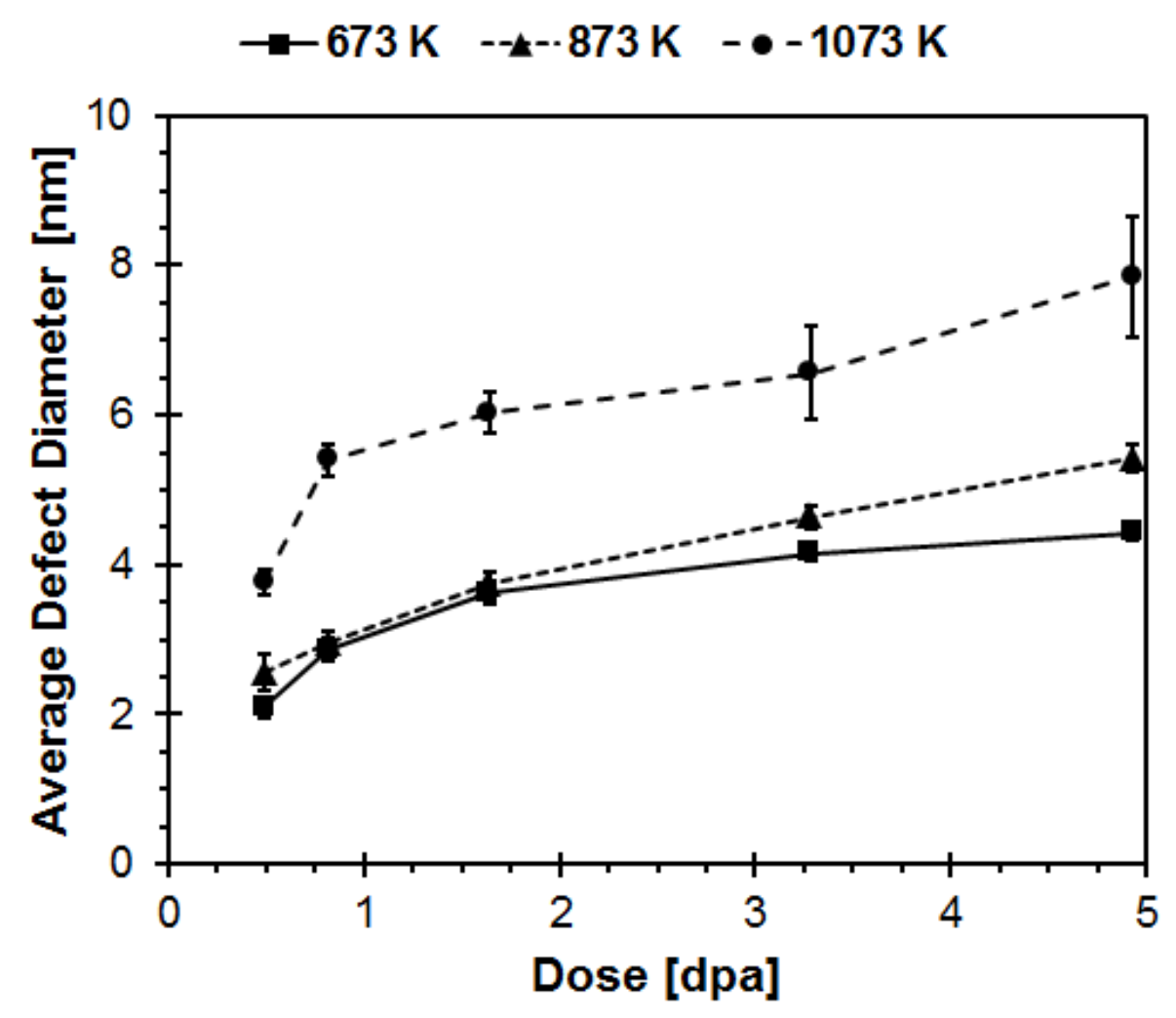

Figure 7: Measurements of mean defect diameter for $\mathrm{ZrC}_{0.9}$ irradiated up to 4.9 dpa at 673 , 873 and $1073 \mathrm{~K}$. The error bars show the $95 \%$ confidence interval for the average of the defect diamter measurements at each dose point. 


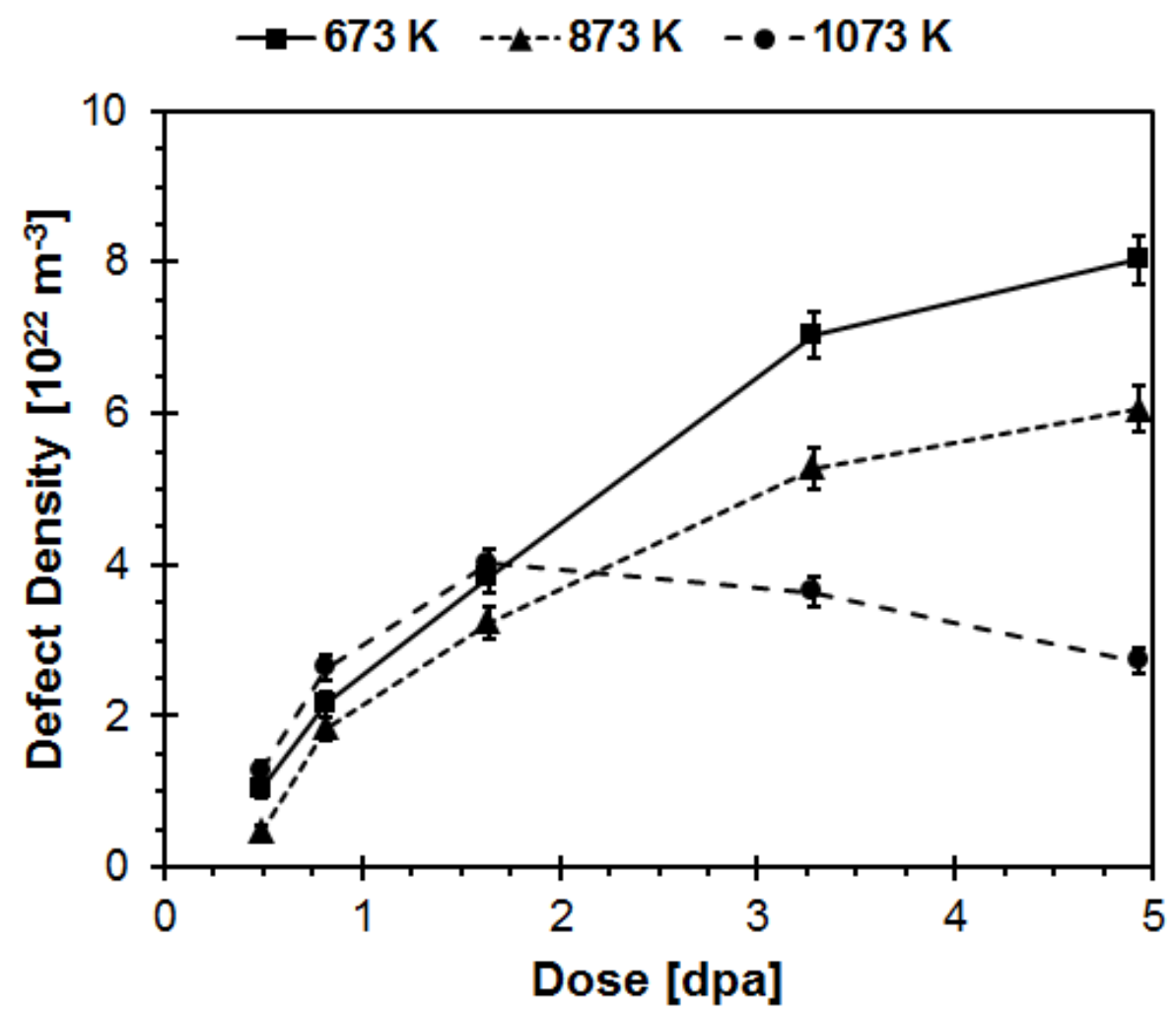

Figure 8: Measurements of defect density for $\mathrm{ZrC}_{0.9}$ irradiated up to 4.9 dpa at 673,873 and $1073 \mathrm{~K}$. The error bars show the $95 \%$ confidence interval associated with the total number of defects counted at each dose point assuming a random spatial distribution of defects.
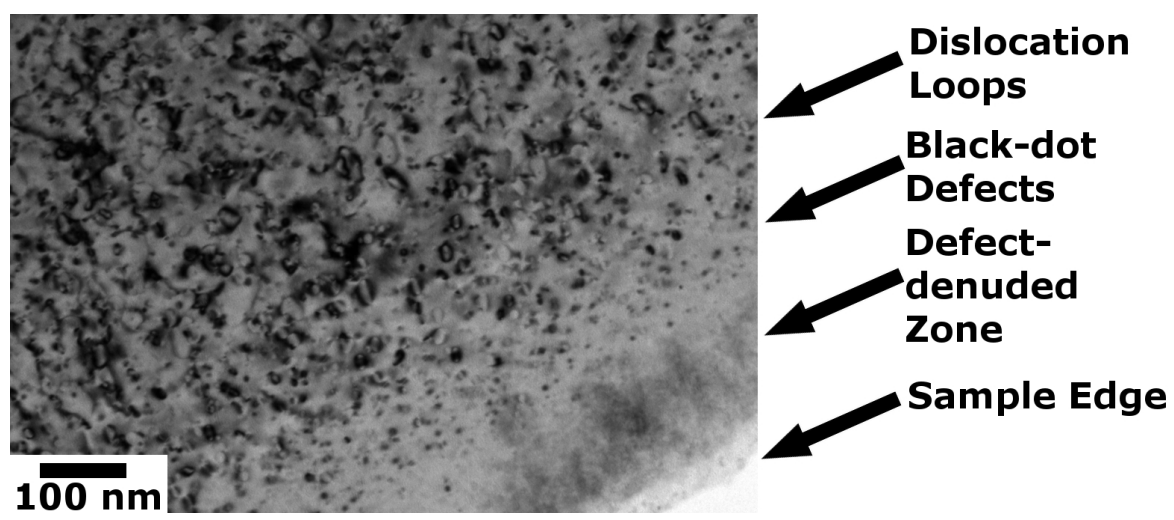

Figure 9: A bright-field image acquired near the sample edge showing the variation in microstructure with thickness after irradiating $\mathrm{ZrC}_{0.9}$ to 6.6 dpa at $1073 \mathrm{~K}$. 


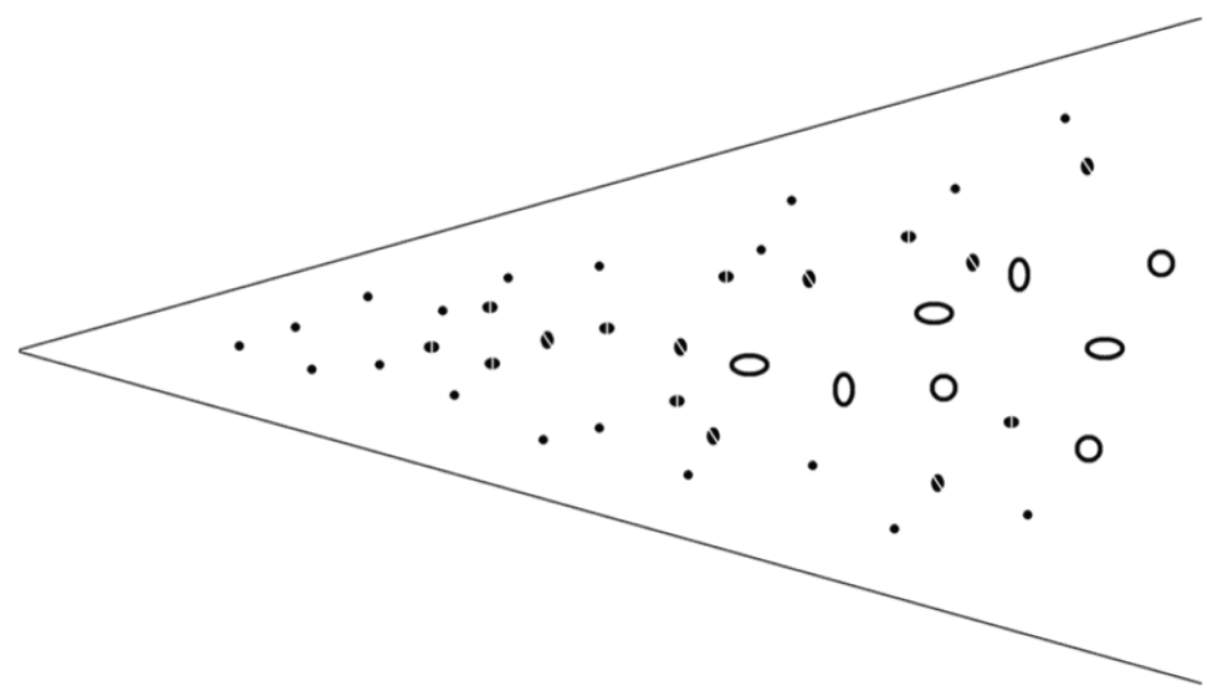

Figure 10: A cross sectional diagram showing the postulated defect structure resulting from the loss of defects to the surface at temperatures above $873 \mathrm{~K}$.
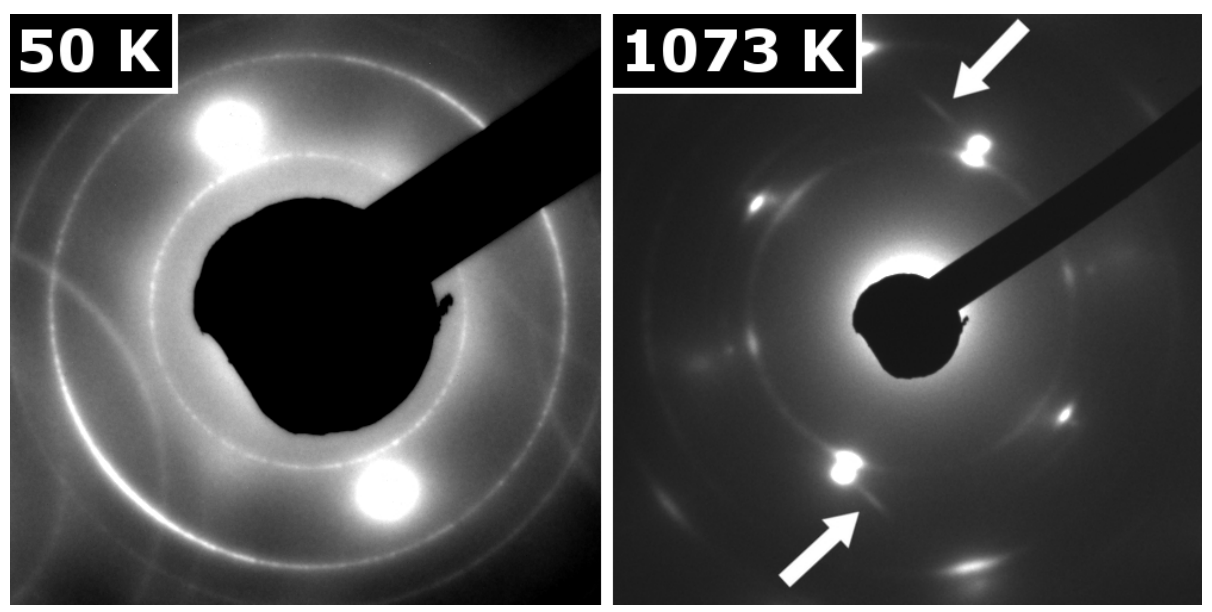

Figure 11: Diffraction patterns acquired after irradiating $\mathrm{ZrC}_{0.9}$ to $16.4 \mathrm{dpa}$ at $50 \mathrm{~K}$ and $1073 \mathrm{~K}$. Diffraction rings developed at both temperatures and streaking occurred at $1073 \mathrm{~K}$ as indicated by the arrows. 

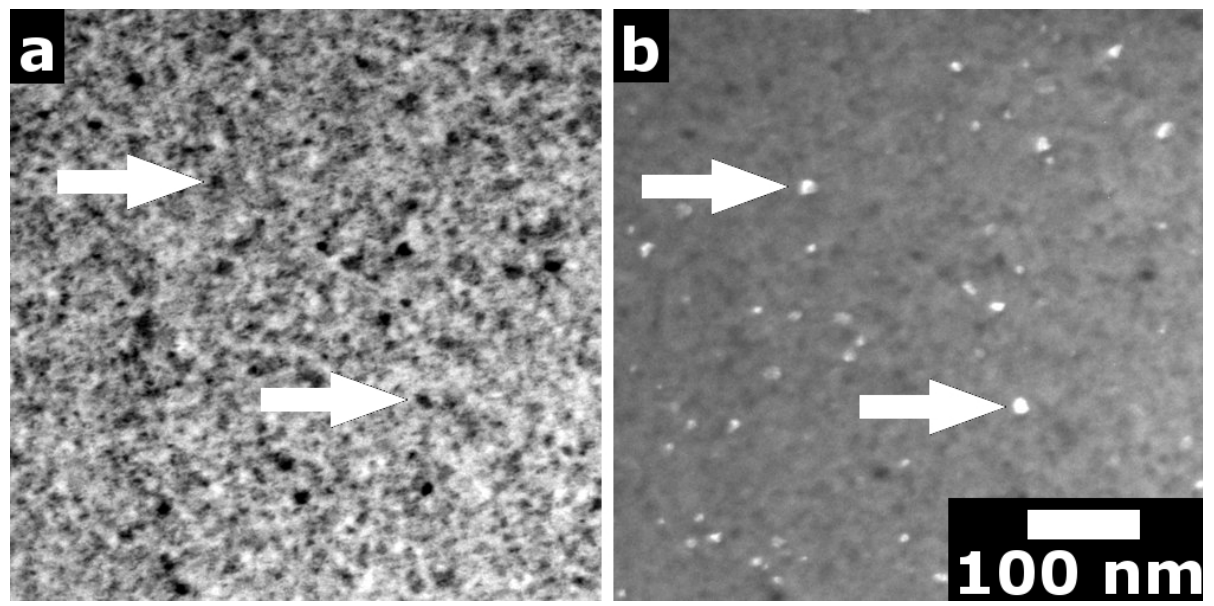

Figure 12: Bright-field (a) and dark-field (b) micrographs recorded at $16.4 \mathrm{dpa}$ at $50 \mathrm{~K}$ showing the same location (corresponding to the left diffraction pattern in Figure 11). The dark-field image is recorded using the the second diffracted ring from the center. Arrows indicate features that are common between the bright-field and dark-field images. 
Table 1: Parameters for electropolishing $\mathrm{ZrC}_{\mathrm{x}}, \mathrm{x}=(0.8,0.9)$.

\begin{tabular}{lc}
\hline Apparatus & Struers Tenupol-5 \\
Electrolyte Solution & $7.5 \%$ perchloric acid \\
& $92.5 \%$ methanol \\
Electrolyte Temperature & $243 \mathrm{~K}$ \\
Voltage & $25 \mathrm{~V}$ \\
Light Stop Value & 60 \\
Pump Flow Rate & 26 \\
\hline
\end{tabular}

Table 2: Input parameters for SRIM simulation.

\begin{tabular}{lc} 
Calculation Type & full cascade \\
Ion Species & krypton \\
Ion Energy & $1000 \mathrm{keV}$ \\
Target Width & $100 \mathrm{~nm}$ \\
Target Density & $6.5 \mathrm{~g} / \mathrm{cm}^{3}$ \\
Target Composition & $\mathrm{ZrC}_{0.9}$ \\
Displacement Energy & $\mathrm{Zr}=22 \mathrm{eV}[28]$ \\
& $\mathrm{C}=17 \mathrm{eV}[28]$ \\
Number of Ions & 10000 \\
\hline
\end{tabular}


Table 3: List of experimental conditions in this study.

\begin{tabular}{ccc}
\hline Material & $\mathrm{T}[\mathrm{K}]$ & Max. Dose [dpa] \\
\hline & 20 & 8.2 \\
& 50 & 16.4 \\
& 300 & 8.2 \\
$\mathrm{ZrC}_{0.9}$ & 473 & 8.2 \\
& 673 & 4.9 \\
& 873 & 8.2 \\
& 973 & 8.2 \\
& 1073 & 16.4 \\
\hline & 50 & 8.2 \\
& 300 & 8.2 \\
& 473 & 8.2 \\
$\mathrm{ZrC}_{0.8}$ & 673 & 8.2 \\
& 873 & 8.2 \\
& 973 & 8.2 \\
& 1073 & 8.2 \\
\hline
\end{tabular}

